\title{
ethic \\ TEORIA PARCIAL DE JUSTIÇA E ESTRUTURA POLÍTICA DEMOCRÁTICA NA TEORIA DE NUSSBAUM
}

\author{
PARTIAL THEORY OF JUSTICE AND POLITICAL DEMOCRATIC \\ STRUCTURE IN NUSSBAUM'S THEORY
}

\author{
NUNZIO ALI ${ }^{1}$ \\ (USP/Brasil) \\ DIANA PIROLI ${ }^{2}$ \\ (UFSC/Brasil)
}

\begin{abstract}
RESUMO
Defendemos neste artigo que o avanço da abordagem das capabilities está entrelaçado firmemente com o desenvolvimento teórico de uma "estrutura política democrática". Para tanto, tomamos como base o modelo normativo de Martha Nussbaum. Em um primeiro momento, nossa investigação discrimina a teoria das capabilities em dois grupos, que aqui designamos de modelos: top down e o bottom up. Por um lado, Nussbaum possui uma abordagem que se move de "cima para baixo", dado que sua teoria parte de questões mais abstratas e somente depois desce para o nível de implementação institucional. Por outro lado, Amartya Sen dispõe de um modelo "de baixo para cima", que inicia das demandas de justiça provindas da esfera pública, subindo em seguida para questões normativas menos concretas. Em um segundo momento, apresentamos a "teoria parcial de justiça" de Nussbaum como um todo, interpretando-a como composta de quatro estágios: (a) primeiro, a elaboração da lista de capabilities, (b) segundo, o processo de validade normativa, (c) terceiro, a estabilidade de uma sociedade justa (d) quarto, a implementação institucional do limiar básico de capabilities. Em relação a esse quarto estágio, em um terceiro momento do artigo, investigamos o relevante papel que a concepção de estrutura política democrática contém na teoria das capabilities da autora. Finalmente, em um último momento, propomos uma reelaboração do limiar básico de capabilities, ou melhor, a lista de Nussbaum, de forma a torná-la mais aberta e democrática. Palavras-chave: Teoria parcial de justiça, capabilities, Nussbaum, Estrutura política democrática.
\end{abstract}

\begin{abstract}
This paper argues that the future of capabilities approach lies on the theoretical development of the democratic political structure. For this purpose, we take into account Martha Nussbaum's normative model. Firstly, we argue that the capability approach can be divided into two main models: the top down and the bottom up. On the one hand, Nussbaum endorses a top-down model, given that it begins from an abstractive theory of partial justice and then it draws the issue of institutional implementation. On the other hand, Amartya Sen advocates the bottom-up model which starts from the immanent demands of justice from public sphere and then up to normative and abstract questions. In the second part, we present Nussbaum's partial theory of justice, arguing that it is mainly composed by four issues: (a) the elaboration of the list of capabilities, (b) the process of normative evaluation, (c) arguments for stability, (d) the institutional implementation of a threshold level of capabilities. About this last topic, in the third part, we focus on the function that a conception of the democratic political structure employs on Nussbaum's capabilities approach. Finally, in the last part, we provide a reformulation of Nussbaum's threshold level of capabilities (the list) in order to make it more adherent with the democratic political structure.
\end{abstract}

Keywords: Partial theory of Justice, Capabilities, Nussbaum, Democratic political structure. 


\section{Considerações iniciais}

Paulatinamente a abordagem das capabilities $^{3}$ avança posições não somente nos direitos humanos e nos direitos dos animais, sobretudo no debate contemporâneo de teorias de justiça, sendo o modelo da teoria parcial da justiça de Nussbaum um dos seus principais representantes. Mas, afinal, o que é uma teoria parcial de justiça? Nussbaum utiliza duplamente essa expressão. Primeiro, para contrastar com uma teoria mais completa, como a teoria de justiça de John Rawls, que propõe formular princípios de justiça para a estrutura básica da sociedade. Segundo, sua parcialidade advém da limitação de seu próprio escopo, que é a promoção institucional de uma vida minimamente digna para os indivíduos e grupos que dela dependem.

Muito se debate acerca das contraposições das abordagens de Martha Nussbaum e Amartya Sen, não obstante pouco se avança especificamente acerca da teoria parcial de justiça da autora ${ }^{4}$, por isso nosso propósito neste artigo é o de preencher esta lacuna. Argumentamos que a sua concepção teórica propõe uma abordagem "suficientarista" para o desenvolvimento de um "limiar básico de capabilities" (a threshold level of capabilities) $)^{5}$. Essa concepção é deveras importante, pois ela corresponde ao padrão mínimo de qualidade de vida que deve ser promovido institucionalmente. A partir dela, proporciona-se condições suficientes para que os indivíduos e grupos que dela dependem tenham possibilidades reais de desenvolvimento de certos functionings (NUSSBAUM, 2013a). Neste sentido, justo é promover de modo suficiente um limiar básico de capabilities ${ }^{6}$. Cabe ressaltar que a nossa reconstrução teórica da concepção parcial de justiça da filósofa não é neutra, pois ela pretende destacar como elemento central a chamada "estrutura política democrática". Fazemos isso, pois acreditamos - tal como Nussbaum - que um renovado foco na dimensão de implementação política seja capaz não somente de responder as objeções e críticas mais contundentes à teoria da autora, sobretudo de entrelaçar de modo mais firme a teoria das capabilities com a democracia. Para ser realisticamente contundente com essa perspectiva, a nosso ver, cabe uma reelaboração da lista das capabilities que seja mais compatível com a ideia de uma estrutura política democrática.

Na primeira seção, apresentamos duas possíveis estratégias teóricas para formular uma possível "teoria de justiça" dentro do paradigma das capabilities. Aqui os designamos de modelo top down e bottom up de capabilities, sendo Nussbaum a representante do primeiro paradigma e Amartya Sen do segundo. Na segunda seção, adentramos propriamente na teoria parcial de justiça da autora, mostrando que é composta de quatro estágios: (a) a formulação da lista capabilities, (b) a justificação normativa, (c) a estabilidade e (d) a implementação. Dando prosseguimento, em uma terceira seção discutimos o papel da "estrutura política democrática" 
na concepção da autora. Por fim, em uma quarta seção, propõe-se um esboço de reelaboração do limiar básico de capabilities de Nussbaum, a partir das três dimensões fundamentais de justiça detectadas por Fraser (2009). Fazemos isso na tentativa de tonar a concepção da lista mais sensível a sua implementação deliberativa e democrática.

\section{Teoria das capabilities: top down e bottom up}

Deste momento em diante tomamos Martha Nussbaum e Amartya Sen como seus principais paradigmas, e propomos duas classificações distintas para uma teoria das capabilities, que aqui são respectivamente denominados de modelos top down e bottom up. ${ }^{7}$

O primeiro paradigma designamos de "teoria das capabilities de tipo top down". Tratase de uma espécie de modelo teórico que inicia como se fosse de cima para baixo, ou melhor, de um elevado grau de abstração teórica, e que depois desce para discussões mais empíricas, tal como o de Martha Nussbaum. Em sua fase inicial, nele se formulam os princípios e as categorias centrais que sustentam a teoria de modo "quase" que independente da empiria (a). Posteriormente, avança-se para o teste dos princípios e pressupostos teóricos previamente elencados (b). Isso se dá através de uma confrontação direta com algumas das teorias contemporâneas concorrentes. Nesse momento há uma dupla verificação: se a sua concepção teórica é possível de resistir (ou não) aos modelos rivais, e se ela melhor responde (ou não) às exigências teóricas previamente debatidas. Por fim, o modelo "desce" completamente de modo a discutir a concepção teórica à luz de dados e casos concretos (c).

De modo oposto, o segundo paradigma é construído como se fosse de baixo para cima e, por isso, aqui optamos por designá-lo de "teoria das capabilities de tipo bottom up". Certamente o modelo de Amartya Sen é o exemplo mais notório. Neste modelo, em um primeiro momento, se apresenta determinado problema empírico que inaugura a discussão (a). Posteriormente, o debate é conduzido para um estágio de idas e vindas entre fatos e pressupostos teóricos até que se encontre uma concepção teórica, que seja suficientemente sólida para resistir e explicar os fatos empíricos (b). Vejamos mais pausadamente a metodologia utilizada por Amartya Sen para desenvolver a sua "ideia de justiça".

O ponto de partida para a construção normativa de uma concepção de "justiça" não deve ser abstraído da realidade, sobretudo derivado de um processo de comparação sobre os múltiplos fenômenos concretos de privação, discriminação e de tudo aquilo que pode ser caracterizado como unfair, ou melhor, não equitativo e injusto, segundo Sen (2011). Destarte, 
sua abordagem é contrária a todo modelo teórico que têm como objeto de justiça unilateralmente a estrutura básica da sociedade, como a de Rawls. Ao contrário, a abordagem de Sen demanda por uma perspectiva de realização, isto é, cujo foco não esteja somente nos arranjos institucionais básicos (embora ele reconheça sua importância), mas que efetivamente considere o que as pessoas são realmente capazes de fazer e de se tornar nas suas escolhas cotidianas. Em outras palavras, seu modelo concerne diretamente os indivíduos (e não as instituições), sendo altamente dependente de pesquisas empíricas que forneçam dados reais sobre como as pessoas realmente vivem as suas vidas. Note como a abordagem de Sen é coerente com a teoria bottom up descrita anteriormente, no qual se tem como ponto de partida a problematização empírica do objeto da investigação (no caso de Sen: como as pessoas realmente vivem suas vidas, e o que elas são capazes de realizar). Posteriormente, sua investigação sobe aos poucos para a parte mais normativa, a qual se formulam as demandas por justiça, a sua materialidade e a sua interconexão com o uso público da razão em uma democracia. Trata-se de um movimento de idas e vindas entre as demandas reais dos indivíduos e uma análise normativa sobre o que a justiça requer. Ainda em A ideia de justiça (2011), o autor apresenta sua concepção, enfatizando que não se trata de "uma teoria de justiça" como no sentido rawlsiano, pois não tem pretensões normativas substanciais (como a formulação de princípios para a estrutura básica da sociedade). Sobretudo, o objetivo de Sen é propor, de modo mais modesto, uma "ideia de justiça” que seja capaz de fornecer uma orientação teórica para comparar sociedades distintas e também para influenciar diretamente as políticas públicas. Propositadamente o modelo do autor descarta abordagens teóricas chamadas de "transcendentais", que questionam como seriam instituições perfeitamente justas. Dois seriam os problemas, segundo Sen (2011). Primeiro, essas teorias transcendentais não são empiricamente viáveis, dado que dificilmente conseguem atingir um consenso real em situações de imparcialidade e de contingenciamento de informações (como no caso da posição original rawlsiana). Segundo, haveria certa tautologia na sua escolha, uma vez que o modelo ideal sempre parece supor já de partida as condições que os sustentam. No lugar de concepções transcendentais de justiça, Sen propõe uma abordagem de tipo comparativa que pergunta como a justiça poderia efetivamente ser efetivada. Nota-se que o segundo estágio da sua construção teórica equivale a uma etapa pendular na qual a normatividade avança em hipóteses teóricas, mas também recua para ser confrontada com casos concretos, para que, enfim, seja delimitada a sua ideia de justiça ${ }^{8}$. O que é totalmente distinto do modelo de Nussbaum que, em contrapartida, parece defender uma abordagem que vem de cima para baixo, isto é, que parte 
inicialmente de questões mais abstratas e, aos poucos, vai descendo para assuntos mais empíricos. Sobre isso, passamos à próxima seção.

\section{Uma teoria parcial de justiça}

Apresentamos, de agora em diante, a teoria parcial de justiça de Nussbaum como um modelo top down de teoria das capabilities que, a nosso ver, é composto de quatro estágios. Ele começa por questões mais abstratas e depois desce para assuntos mais concretos. O primeiro estágio é a apresentação do limiar básico de capabilities no formato de uma lista. O segundo é o da validade normativa da teoria. O terceiro é o da estabilidade de uma sociedade justa. Por fim, o quarto estágio é o de implementação. Juntos, segundo a nossa interpretação, esses quatro estágios compõem a sua teoria parcial da justiça. Nosso objetivo aqui é não somente o de distinguir, sobretudo, o de apresentar brevemente cada um de seus momentos, a fim de sanar um recorrente erro de redução da teoria parcial de justiça de Nussbaum a somente um determinado estágio, qual seja: o da exposição da sua lista de capabilities. Para desenvolver esse formato de exposição da teoria de Nussbaum, tomamos principalmente como base as obras Creating Capabilities (2011a) e Fronteiras da Justiça (2013a), que são os dois livros centrais nos quais a autora aprofunda a sua teoria parcial de justiça de modo mais próximo do que fazemos aqui. Baseamo-nos no capítulo quatro de Creating Capabilities (2011a) especialmente a sequência de apresentação das seções - sobretudo por acreditar que nele está contida a forma mais promissora de estruturação da sua teoria como um todo.

Em paralelo aos quatro estágios, sustentamos que há quatro perguntas que orientam o horizonte de suas formulações. A pergunta: como seria uma vida humana dignamente vivida? impulsiona o primeiro estágio da formulação da teoria. Para tanto, Nussbaum apresenta uma lista de capabilities como resposta. A segunda pergunta questiona: quais seriam as bases legítimas de justificação da teoria? Nussbaum responde que sua abordagem está em afinidade com uma concepção liberal de justiça política, que é universal, equitativa e livre de valores abrangentes (freestanding). Dando prosseguimento: como é possível uma sociedade ser não somente justa, mas também estável ao longo tempo? Essa pergunta conduz ao terceiro núcleo de discussão, propondo que a estabilidade depende do manejo saudável das emoções políticas e do combate daquelas que são socialmente perigosas. Por fim, como implementar a teoria parcial de justiça? É na resposta a esta pergunta que está, na visão de Nussbaum (e também na nossa), o futuro da teoria das capabilities. Passemos ao primeiro estágio. 


\section{(a) Lista de capabilities}

Certamente a etapa de formulação da lista é a parte da teoria de Nussbaum mais conhecida e igualmente criticada. Suas críticas se concentram tanto neste quesito, a ponto de resumirem o restante da sua teoria parcial de justiça a este estágio, ocultando o seu desenvolvimento posterior ${ }^{9}$. De fato, a proposição da lista é fundamental dentro da concepção teórica da autora - e, por isso, é correto frisar o seu protagonismo - todavia ela é somente uma parte da abordagem, uma espécie de "ponto de partida" que integra a composição de sua teoria parcial de justiça como um todo.

Nussbaum situa sua lista de capabilities como um dispositivo teórico que concorre diretamente com o paradigma dos "bens primários" de John Rawls (1999). Ela argumenta que seu objetivo não é o de criticar os limites da concepção de bens primários rawlsianos - pois isto Amartya Sen (2011) já o fez - sobretudo, seu objetivo é o de se apropriar da sua intuição de fundo, de modo a torná-la compatível com a abordagem das capabilities. Neste esforço, cabe cuidadosamente notar que a autora não constrói uma lista de capabilities para substituir os bens primários rawlsianos, mas para equivaler a eles dentro em sua abordagem ${ }^{10}$.

Da mesma forma que Rawls (1999) apresenta os bens primários - que são renda e riqueza, direitos e liberdades, oportunidades de carreira e as bases sociais do autorrespeito como uma espécie de teoria fraca de bem (a thin theory of good) que pode ser universalmente compartilhada por qualquer pessoa racional na posição original ${ }^{11}$, Nussbaum também interpreta a composição de sua lista de forma similar, definindo-a como certa teoria fraca de bem, que dá substancialmente corpo à ideia de uma vida suficientemente digna. Portanto, a lista define ex ante os conteúdos que integram o limiar básico de capabilities, que podem ser universalmente compartilhados por quaisquer grupos distintos culturalmente. Neste sentido, sua lista - tal como os bens primários - incorpora uma concepção enxuta de bem que apresenta uma vida boa como aquela que é composta por um padrão mínimo de capabilities. Sobretudo, esse limiar básico de capabilities funciona duplamente como (a) uma concepção fraca de bem e (b) um padrão para medir a real posição social dos indivíduos na sociedade. Assim como os bens primários rawlsianos fornecem uma métrica para identificar a posição social dos grupos mais e menos favorecidos na sociedade, o conteúdo objetivo da lista permite que se olhe para o mundo e se compare efetivamente o grau de decência de vida dos indivíduos. Uma vez que são estabelecidas as carências e tornado possível a comensurabilidade das suas disparidades, podese avançar para a proposição de políticas públicas adequadas para remediá-las. 
Para além dos objetivos (específicos) dos bens primários de Rawls - novamente, o de fornecer uma concepção fraca de bem e um padrão de métrica para classificar as posições sociais - Nussbaum, ao contrário, altera este aspecto funcional e torna a lista um elemento central da qual deriva todo o restante da sua teoria. Se na teoria rawlsiana os bens primários tinham um papel funcional, em Nussbaum a lista se torna lócus de emanação da qual deriva toda a abordagem que se segue.

A lista de capabilities possui diversas características. Vejamos algumas delas. Ela atua como uma (a) corporificação da ideia de dignidade. Neste sentido, Nussbaum (1997) nota que o esforço da teoria é postular normativamente uma concepção de vida digna, cujos os itens da lista forneçam certa substancialidade para uma concepção tão abstrata quanto a de "dignidade". Uma segunda característica é que a lista tem como alvo prioritário (b) os indivíduos e depois os grupos. Sua lista se concentra em um (c) combinado de capabilities que abrange desde condições internas (como autorrespeito) e externas (saúde, alimentação, etc.). Uma outra característica é que a lista é (d) heterogênea, pois abrange qualitativamente dez áreas distintas. Ao dar prosseguimento, (e) algumas capabilities requerem igualdade e outras adequação de distribuição, por exemplo, as capabilities políticas devem ser igualmente distribuídas, em outros casos pode ser suficiente sua mera adequação. A lista é (f) propositadamente abstrata, a fim de que possa adaptar-se ao interior de cada cultura. Ela representa ( $g$ ) apenas uma proposta possível que está aberta ao debate político, portanto é capaz de escrutínio. Por fim, a lista $(h)$ não é idealmente utópica, mas uma ideia que é possível de aspiração real ${ }^{12}$ - neste sentido, ela é uma "utopia realista"13. Abaixo reproduzimos a lista em sua íntegra.

\section{AS CAPABILITIES HUMANAS CENTRAIS}

1. Vida. Ter a capacidade de viver até o fim de uma vida humana de duração normal; não morrer prematuramente, ou antes que a própria vida se veja tão reduzida que não valha a pena vivê-la.

2. Saúde física. Ser capaz de ter boa saúde, incluindo a saúde reprodutiva; de receber uma alimentação adequada; de dispor de um lugar adequado para viver.

3. Integridade fisica. Ser capaz de se movimentar livremente de um lugar a outro; de estar protegido contra ataques de violência, inclusive agressões sexuais e violência doméstica; dispor de oportunidades para a satisfação sexual e para a escolha em questões de reprodução.

4. Sentidos, imaginação e pensamento. Ser capaz de usar os sentidos, a imaginação, o pensamento e o raciocínio - e fazer essas coisas de um modo "verdadeiramente humano", um modo informado e cultivado por uma educação adequada, incluindo, sem limitações, a alfabetização e o treinamento matemático e científico básico. Ser capaz de usar a imaginação e o pensamento em conexão com experimentar e produzir obras ou eventos religiosos, literários, musicais e assim por diante, da sua própria escolha. Ser capaz de 
usar a própria mente de modo protegido por garantias de liberdade de expressão, com respeito tanto à expressão política quanto artística, e liberdade de exercício religioso. Ser capaz de ter experiencias prazerosas e evitar dores não benéficas.

5. Emoções. Ser capaz de manter relações afetivas com coisas e pessoas fora de nós mesmos; amar aqueles que nos amam e que se preocupam conosco; sofrer na sua ausência; em geral, ser capaz de amar, de sentir pesar, sentir saudades, gratidão e raiva justificada. Não ter o desenvolvimento emocional bloqueado por medo e ansiedade. (Apoiar essa capability significa apoiar formas de associação humana que podem revelar-se cruciais para seu desenvolvimento.)

6. Razão prática. Ser capaz de formar uma concepção de bem e de ocupar-se com a reflexão crítica sobre o planejamento da própria vida. (Isso inclui proteção da liberdade de consciência e de prática religiosa.)

7. Afiliação.

A. Ser capaz de viver com e voltado para os outros, reconhecer e mostrar preocupação com outros seres humanos, ocupar-se com várias formas de interação social; ser capaz de imaginar a situação do outro. (Proteger essa capability significa proteger as instituições que constituem e alimentam tais formas de afiliação e também proteger a liberdade de associação e de expressão política.)

B. Ter as bases sociais de autorrespeito e não-humilhação; ser capaz de ser tratado como um ser digno cujo valor é igual ao dos outros. Isso inclui disposições de não discriminação com base em raça, sexo, orientação sexual, etnia, casta, religião e origem nacional.

8. Outras espécies. Ser capaz de viver uma relação próxima e respeitosa com animais, plantas e o mundo da natureza.

9. Lazer. Ser capaz de rir, brincar e gozar de atividades recreativas.

10. Controle sobre o próprio ambiente.

A. Político. Ser capaz de participar efetivamente das escolhas políticas que governam a própria vida; ter o direito à participação política, proteções de liberdade de expressão e associação.

B. Material. Ser capaz de ter propriedade (tanto de bens imóveis quanto de móveis) e de ter direitos de propriedade em base igual à dos outros; ter o direito de candidatar-se a empregos em base de igualdade com os demais; ter a liberdade contra busca e apreensão injustificadas. No trabalho, ser capaz de trabalhar como ser humano, exercendo a razão prática e participando de relacionamentos significativos, de reconhecimento mútuo com os demais trabalhadores. (NUSSBAUM, 2013a, pp. 91- 93 ${ }^{14}$ )

\section{(b) Justificação normativa}

Após elaborada a lista, a teoria parcial da justiça segue para o processo de validade normativa, no qual é testado se a sua justificação à nível político e moral consegue fornecer boas razões (racionais) para a legitimidade e aderência à teoria das capabilities. Este processo ocorre em uma série de procedimentos, comparações e confrontamentos - baseando-se no equilíbrio reflexivo rawlsiano - com o qual se busca ajustes sucessivos entre concepções teóricas e julgamentos morais, a qual a cada estágio se obtém uma maior claridade sobre justiça 
social (NUSSBAUM, 2011a, pp. 77-78). Assim, trata-se de um processo de confrontamento teórico, no qual se faz um exame normativo em vários rounds de justificação ${ }^{15}$. Nesta etapa o modelo das capabilities deve mostrar-se teoricamente mais sofisticado do que seus concorrentes naquilo que concerne à promoção das bases para uma vida suficientemente digna para todos aqueles indivíduos e grupos que dependem das principais instituições políticas (NUSSBAUM, 2011a, 2013a).

Três são as etapas de teste, que aqui designamos de etapa moral, etapa política e etapa de validação global. Primeiro ocorre o teste moral, na qual a concepção de justiça deve ser capaz de ser apresentada como "universalmente" válida, ou seja, incluindo todos os indivíduos independentemente das especificidades da sua nação e cultura. E também deve ser capaz de mostrar-se duplamente "igualitária": (a) apta (e talvez até mais vantajosa) na proteção igual de uma vida decente a todos os indivíduos que dependem das instituições políticas, (b) capaz de defender que todos tenham direito igual ao limiar básico de capabilities, bem como que seu bem-estar não sobrepujado em nome da maioria da maioria. Esta é a exigência moral ${ }^{16}$.

Em um segundo estágio prossegue o teste político. Aqui, a teoria parcial de justiça deve ser capaz de ser apresentada como livre de valores abrangentes (freestanding), ou seja, ela não pode estar fundamentada politicamente em uma concepção abrangente de bem. Para tanto, sua abordagem precisa atuar como um paradigma “(...) unicamente para propósitos políticos, e não como um guia abrangente para uma vida boa" (NUSSBAUM, 2011a, p. 90, tradução nossa). Seguindo o espírito de Rawls (1999, 1996), Nussbaum defende que uma concepção de justiça política deve ser capaz de passar em uma espécie de teste da imparcialidade ética, dado que não deve fundamentar-se em uma concepção abrangente de bem, mas sim em uma concepção de justiça. Esta é a exigência política.

Por fim, o terceiro estágio de justificação refere-se ao escopo de sua atuação. Aqui, a teoria parcial de justiça deve ser capaz de atuar não somente a nível local e doméstico, mas também a nível global ${ }^{17}$. Neste sentido, o limiar básico de capabilities deve ser capaz de ser apresentado como uma concepção capaz de se tornar uma base de acordo comum não somente a nível interior (local e domestico), sobretudo "global" como uma espécie de acordo que pode ser sustentado racionalmente por diversas culturas - atuando como uma espécie de "acordo transcultural" (cross-cultural agreement) endossado por quaisquer grupos étnicos, desde que razoáveis (NUSSBAUM, 2013a, 2000) ${ }^{18}$. Nussbaum utiliza a concepção de "acordo transcultural" para defender que é possível postular normativamente a ideia de um acordo comum entre culturas distintas sobre as condições mínimas para uma vida decente. Esta é a 
exigência de seu escopo de atuação. Caso a concepção teórica seja capaz de passar por esses três testes (moral, político e de escopo), então ela poderá ser considerada como uma concepção racional e justificável sob o ponto de vista normativo do que a justiça requer.

\section{c) Estabilidade social}

Após a publicação de Fronteiras da Justiça (2013a) e Creating Capabilities (2011a), Nussbaum se dedica com profundidade ao desenvolvimento da temática da "estabilidade" de uma sociedade justa, destacando o papel positivo da psicologia moral no cultivo de emoções socialmente construtivas, e o seu papel negativo na avaliação do controle de emoções perniciosas como o nojo, a vergonha, o ressentimento e o medo ${ }^{19}$. As principais instituições políticas não devem ser unicamente justas no sentido moral e político (já vistos), sobretudo precisam ser estavelmente justas, ou seja, serem capazes de criar a longo prazo uma cultura política pública, que mobilize positivamente a aderência dos indivíduos e grupos às instituições e, negativamente, os afaste de psicologias sociais perigosas ${ }^{20}$.

Em uma das suas principais obras sobre emoções políticas - Political Emotions (2013b) - Nussbaum propõe as bases teóricas para um modelo de estabilidade social que seja capaz de fornecer o suporte emocional necessário para a promoção das demandas de justiça. Ela argumenta que o papel redistributivo das instituições precisa considerar não somente as parcelas distributivas, mas também os sentimentos que serão gerados a partir delas na cultura política pública. Por exemplo, certas medidas redistributivas como aquelas de taxação de riqueza e de transferência de renda - por exemplo, através de programas de combate à pobreza e de ações afirmativas - sem seu devido suporte emocional de apoio, podem gerar consequências indesejadas como o ressentimento e a inveja, criando um ambiente hostil não somente para os beneficiários de programas sociais como também para as próprias instituições. Deste modo, as instituições devem ser capazes de neutralizar certas tendências para o "mal", no qual o forte desejo primitivo de expor alguns grupos ou indivíduos publicamente à vergonha, bem como de expressar nojo a eles, pode incitar uma cultura pública perniciosa, que incentiva crimes de ódio, discriminação e humilhação (NUSSBAUM, 2003).

\section{(d) Implementação}

Como realizar as condições para uma vida digna? No quesito "implementação" esta é a pergunta a ser feita, estando nela o principal o avanço teórico hodierno da abordagem das 
capabilities. Em resposta à pergunta supracitada, Nussbaum (2011a) alerta que não há receita pronta para o processo de implementação, uma vez que o modelo das capabilities depende de um aparato institucional que seja capaz de se adaptar aos contextos específicos (locais, políticos, culturais, geográficos, etc.). Como fornecer as bases normativas para sua implementação? O primeiro ponto é toda postura autoritária e paternalista de implementação é injusta, seja ela estatal ou global. Embora o Estado no plano normativo tenha soberania para escolher os meios de implementação da lista, suas diretrizes devem estar de acordo com os direitos humanos. Outro ponto relevante é que a realização plena de todos os quesitos da lista de capabilities não é obrigatória. De modo menos pretensioso, a teoria parcial de justiça defende que é justo o fornecimento de um limiar básico de capabilities, que devem ser promovidos de acordo com as condições reais domésticas e locais de cada estado. Todavia, qual é esse limiar? Ex ante se conhece normativamente a resposta (no formato de uma lista), mas ex post a resposta permanece em aberto, pois ela depende de análises e de dados concretos sobre as reais condições socioeconômicas de cada região. A teoria, no máximo, pode atuar como base de recomendação normativa, devendo sempre ser trabalhada em conjunto com outras disciplinas (a economia, a ciência política, etc.).

Quem é o destinatário da teoria parcial de justiça? E quem deve promover a sua implementação? Certamente essas duas perguntas são de grande valia para a teoria das capabilities como um todo, uma vez que já desde os primeiros trabalhos de Amartya Sen (1993) objetiva-se influenciar efetivamente a métrica e a concepção de desenvolvimento humano (PNUD/ONU); portanto, a teoria das capabilities carrega consigo uma preocupação central com o processo de implementação desde sua geração. Com Nussbaum (2013a) não é diferente, para ela as instituições possuem um importante papel na promoção de condições sociopolíticas que possibilitem o desenvolvimento (suficiente) das capabilities humanas centrais. Esta responsabilidade na implementação é compartilhada triplamente (a) pela estrutura básica da sociedade, (b) pelos agentes e pelas instituições locais e domésticas, e (c) pelos atores globais. Embora os destinatários da teoria parcial de justiça sejam os indivíduos e os grupos, a autora confere um papel forte para a estrutura básica da sociedade e as suas instituições (locais, domésticas e globais), pois sem elas a implementação não é realizável.

Ao dar aprofundamento à investigação, seguimos para os exemplos de instituições mencionados pela autora. A nível doméstico ela se refere às instituições que compõe a estrutura básica da sociedade com destaque ao sistema jurídico-político do constitutional law, que é formado pela Constituição e pelo o conjunto de suas interpretações pela Suprema Corte. 
Essa estrutura incluirá o Sistema legislativo, os tribunais, a administração e pelos menos algumas agências administrativas, as leis que definem a instituição da família e a distribuição de privilégios entre seus membros, o Sistema tributário e de assistência social, as linhas gerais do sistema de justiça penal e provavelmente também outras estruturas. (NUSSBAUM, 2013a, p. 383)

Tomadas em conjunto, essas instituições (sistema legislativo, os tribunais, agências administrativas, etc.) compõem o design institucional doméstico que protege e distribue equitativamente os direitos, as liberdades e as parcelas redistributivas (NUSSBAUM, 2011a). A nivel local têm-se como paradigma as instituições que integram a sociedade civil, como as agências administrativas não-governamentais e as empresas (NUSSBAUM, 2011a, p. 178). Recorrentemente Nussbaum cita como exemplo o programa indiano Self Employed Women's Association (SEWA), que promove a autonomia das mulheres indianas seja na perspectiva econômica (que as ajuda a ter uma renda fixa mensal), seja no formato moral (pois suporta uma valorização do autorrespeito delas). Não obstante, somente a atuação doméstica e local não é suficiente para um mundo globalizado, dado que as redes de interação entre os países são demasiadamente estreitas, e isso é um ponto positivo. A nível global os órgãos internacionais como a ONU, o FMI, o Banco Mundial e demais organizações não-governamentais (como a OXFAM) também possuem responsabilidade na implementação institucional do limiar básico de capabilities (NUSSBAUM, 2013a). Essas instituições podem agir regulando a manutenção dos acordos internacionais sobre direitos humanos, propondo estratégias socioeconômicas para o desenvolvimento das nações mais pobres, como também elaborando outros programas de cooperação internacional (NUSSBAUM, 2000). Claramente a "soberania nacional" tem sua prioridade na teoria da autora, pois é a partir dela que a nação e seus cidadãos têm autonomia suficiente para deliberar e decidir sobre as próprias leis e o limiar de implementação das capabilities. Todavia, a cooperação internacional não deve ser descartada (NUSSBAUM, 2013a). Este movimento pendular entre estruturação local, doméstica e global caminha para que os âmbitos atuem em conjunto, a fim de promover uma vida minimamente digna para os indivíduos ${ }^{21}$.

\section{Estrutura política democrática}

É recorrente a crítica da suposta ausência do aspecto democrático e deliberativo da teoria de Nussbaum, principalmente acusando-a de impor uma lista de capabilities de cima para baixo, 
que viria como se fosse do alto da sua cabeça, descendo para as práticas políticas. Ela discorda recorrentemente que sua abordagem seja autoritária e avessa à deliberação pública, ao contrário, é correto definir sua lista como pré-política e não apolítica, pois ela não exclui a relevância do aspecto da deliberação na esfera pública, somente o posterga para o último estágio da teoria. Diz a autora: "A minha abordagem também respeita a importância da deliberação" (NUSSBAUM, 2011a, p. 74, tradução nossa), todavia, de modo distinto de Amartya Sen, que defende sua atuação diretamente na esfera pública. A ideia de deliberação política em Nussbaum é distinta e mais ampla do que a de Sen, diz ela: “(...) em uma democracia em desenvolvimento, a deliberação tem seu lugar em diferentes níveis e contextos distintos” (NUSSBAUM, p. 74, tradução nossa). Os cidadãos podem deliberar sobre os princípios políticos, sobre os arranjos institucionais, sobre a lista de capabilities, sobre sua correta interpretação, sobre a legislação, a constituição, etc. A lista representa somente um ponto de partida que está aberto ao escrutínio público, podendo ser efetivamente alterada ou adaptada de acordo com as peculiaridades locais. Em última instância, cabe às instituições domésticas e locais a soberania de decisão (e não a Nussbaum). Destarte, a autora concorda que sua teoria caminha metodologicamente de cima para baixo; todavia, discorda de que sua teoria anule as práticas democráticas de deliberação pública, dado que elas são fundamentais na etapa de implementação, que como visto é o momento o qual se discute a possibilidade real de realização do limiar básico das capabilities.

Nussbaum não somente tem estofo teórico para se defender das acusações de ser "antipolítica", como também é capaz de inverter seu destinatário, afirmando que seu modelo tem mais substancialidade teórica-normativa quanto à complementaridade entre capabilities, justiça e democracia do que o modelo de Amartya Sen, que é geralmente considerado o autor cuja teoria é mais sensível às práticas democráticas ${ }^{22}$. Para ela, a discussão sobre democracia em Sen não passa de "mero aceno" ao assunto (NUSSBAUM, 2011a, p. 180). Embora, o autor destaque constantemente a relação entre teoria das capabilities e democracia, falta a ele certa análise normativa mais profunda acerca da estrutura de sustentação, dos princípios e critérios que podem ser justificados para julgar as escolhas efetivas. Nas palavras de Nussbaum: “(...) Sen ainda não ofereceu nenhuma abordagem detalhada sobre como o procedimento democrático pode trabalhar as questões estruturais" (2011a, p. 178, tradução nossa). Uma proposta de democracia deliberativa feita nestes termos, mostra-se teoricamente insuficiente, uma vez que se limita ao que "o povo manda" (people rules). Em outros termos, a maioria participa, vota e escolhe, carecendo de um arcabouço substancial de orientação que forneça 
critérios e princípios objetivos para julgar a validade de suas escolhas e argumentos sob o ponto de vista da justiça (NUSSBAUM, 2011a).

Agora podemos retornar à pergunta que nos interessa, afinal, o que significa a estrutura política? Para Nussbaum, ela abrange o conjunto de princípios e demais aspectos institucionais que fundamentalmente influenciam direta ou indiretamente a qualidade de vida dos indivíduos e grupos que dela dependem (2011a, p. 166). Em Creating Capabilities (2011a) ela elenca alguns dos elementos que a integram, como aquelas instituições que estruturam o "procedimento de votação", o "processo de revisão judicial", bem como aquelas que determinam o papel dos grupos políticos e das suas limitações no processo de deliberação e decisão. Particularmente nos interessa as considerações tecidas em Creating Capabilities (2011a), Fronteiras da Justiça (2013a) e em artigos publicados por ela, como Capabilities, Entitlements, Rights: Supplementation and Critique (2011b) e Political liberalism and global justice (2015) nos quais se pode perceber que a autora destaca a estrutura política, mas não de qualquer tipo, pois interessa a ela a "estrutura política democrática".

Por que efetuar uma investigação da estrutura política democrática na abordagem das capabilities? Fornecemos três motivos. Primeiro, a própria autora defende que o avanço da teoria das capabilities está nessa investigação. Nussbaum é explicita nesse ponto: “o principal desafio para a abordagem das capabilities no futuro é pensar modos mais sistemáticos para lidar com a estrutura política" (2011a, p. 180) ${ }^{23}$. Segundo, a teoria das capabilities de tipo top-down é recorrentemente pressionada para sair do nível abstrato da elaboração da lista, a fim de se inserir em debates específicos acerca da possibilidade de efetivação real de seu modelo. Terceiro, sua implementação não pode ocorrer de qualquer maneira, sobretudo deve estar inserida no modelo democrático, pois é a forma de governo mais apropriada para se adaptar ao pluralismo das sociedades contemporâneas. Dados esses três argumentos, sua teoria parcial de justiça se movimenta de modo a entrelaçar o modelo das capabilities e o de democracia, ou melhor, de uma estrutura política democrática, endossando que a democracia não requer somente sua sustentação enquanto um valor cultural importante, sobretudo cabe dar um passo além para investigar a sua "estruturação normativa", ou seja, suas instituições, seus critérios e princípios.

A conjunção entre capabilities e política é fundamental. Por muito tempo a abordagem das capabilities proporcionou notória influência ao retornar o aspecto fundamental da autonomia dos indivíduos em uma concepção de justiça, não obstante ela deve dar um passo além da agência individual, a fim de teorizar de modo mais sistematizado sobre as estruturas e 
as instituições políticas. Certamente, a nível metodológico, a filósofa aproxima sua teoria do modelo "ideal" de teoria das capabilities, não obstante longe de querer desenhar em uma prancheta estruturas jurídico-políticas perfeitas - que nunca serão alcançadas - Nussbaum apresenta abstratamente certa estrutura normativa de justiça política, que pode ser universalmente endossada por todos os indivíduos livres e iguais. Deste modo, o propósito de uma teoria ideal das capabilities, como a de Nussbaum - em contraposição a uma teoria nãoideal como a de Sen - é de fornecer uma concepção parcial de justiça fundamentada normativamente, que acomode o uso abstrato da razão junto com pesquisas empíricas, deste modo alcançando uma teoria das capabilities substantiva que seja capaz de fornecer um limiar básico de capabilities, bem como critérios e princípios sobre o que uma concepção parcial de justiça requer das instituições.

\section{Reelaborando o limiar básico de capabilities}

Ao longo da reconstrução da teoria parcial de justiça de Nussbaum, algumas vantagens do modelo normativo top down das capabilities ficaram evidentes. Por exemplo, (a) ela possui uma estrutura normativa mais robusta do que Sen, (b) que contém princípios e critérios objetivos para julgar a estruturação básica das instituições. Outrossim, (c) ela oferece una lista de capabilities, (d) que fornece as bases para medir o grau de decência das condições de vida. Ela possui (e) claros compromissos normativos morais com o universalismo e com igualitarismo. Destarte, (f) ela também tem compromissos normativos políticos com uma concepção de justiça política, que seja fundamentada livre de concepções abrangentes de bem. Aborda (g) certo pluralismo de escopos que atua a nível loca, doméstico e global. Contudo, reconhecemos que a amplitude de sua lista ainda continua a incomodar grupos alinhados a Nussbaum ou antagonistas a ela. Isso ocorre, pois, o artifício teórico da lista adquiriu grandes proporções, convertendo-se em um nó no qual a abordagem da autora parece não mais escapar. Em função disso, Nussbaum é recorrentemente criticada por ter uma teoria autoritária e perfeccionista $^{24}$. Por um lado, defendemos que a ênfase na estrutura política democrática - que integra o conjunto teórico da autora - é capaz de oferecer uma defesa contra essas objeções. Por outro lado, concordamos que ainda assim permanece certo descontentamento entre a lista de capabilities - tal como elaborada por Nussbaum - e uma estrutura política democrática. A fim de sanar esse imbróglio, sugerimos manter o espírito da autora, isto é, o de fornecer uma metragem mais objetiva sobre as condições suficientes para uma vida digna, todavia, reduzindo 
alguns dos itens da lista ou reformulando sua própria estrutura, de modo a torna-la factível e cada vez mais aberta.

Destarte, nossa proposta substituí a linguagem da lista para o léxico limiar básico de capabilities, dado que ele próprio é recorrentemente usado por Nussbaum em seus últimos trabalhos $^{25}$. Assim, no lugar de defender um conjunto de "itens" que compõe suficientemente uma vida digna, a teoria das capabilities limitar-se-ia à organização normativa das "dimensões da justiça" com as quais ela deve concentrar-se. A nosso ver, esse horizonte normativo abrangeria três importantes campos de investigação da justiça social hodierna, quais sejam: a redistribuição, o reconhecimento e a representação política (FRASER, 2003, 2009) ${ }^{26}$.

Segundo Nancy Fraser (2003), quando se pergunta o que é a justiça? uma polissemia de significações emerge com força. Em sua obra paradigmática obra Social Justice in the Age of Identity Politics: Redistribution, Recognition, and Participation (2003), a autora narra como os movimentos sociais, as instituições políticas e demais agentes nas sociedades contemporâneas passam a fragmentar, isto é, separar a justiça nos mais variados escopos e dimensões. Ela nota que há um movimento de separação das dimensões da justiça (principalmente em redistribuição e reconhecimento), como também há uma tentativa de tornalas incomensuráveis entre si, criando lacunas entre questões redistributivas (de demandas materiais como propriedade, renda e riqueza) e de reconhecimento (aquelas de teor simbólico como o respeito e a estima nas demandas das minorias étnicas, culturais e de gênero). Posteriormente, Fraser (2009) acrescenta uma terceira dimensão: chamada de representação, que não somente configura um outro escopo da justiça (concernente às questões políticas), sobretudo atua como elo de conexão entre as duas dimensões anteriores, sendo uma espécie de charneira que atua para fazer o movimento entre uma e outra. Ela nota que, embora cada dimensão represente demandas analiticamente distintas de justiça, elas não estão desacopladas. Justiça redistributiva, justiça de reconhecimento e justiça política são concepções particulares que compõe a ideia de justiça social, por isso elas não estão isoladas entre si. O erro ocorre quando as demandas redistributivas tentam anular as demandas de reconhecimento, as políticas as redistributivas, e vice-versa, apresentando-as como falsas demandas que tentam ofuscar sua única e verdadeira dimensão de justiça (seja ela redistribuição, reconhecimento ou representação). É justamente contra uma concepção monista de justiça que a autora argumenta (FRASER, 2003, 2009). Para ela, a justiça é plural e comporta várias dimensões que não se anulam entre si. Contra uma visão monista de justiça, cabe a toda e qualquer teoria de justiça 
alinhar-se, inclusive uma teoria parcial de justiça como aquela defendida por Nussbaum na abordagem das capabilities.

Aqui propomos repensar o limiar básico de capabilities como sendo composto desses três horizontes normativos, uma vez que toda e qualquer concepção de justiça hodierna precisa ser capaz de lidar com a polissemia das dimensões da justiça (FRASER, 2009, 2003). Deste modo, cruzamos as teorias de Nussbaum e Fraser. O primeiro horizonte daria conta das capabilities ligadas à justiça redistributiva - neste sentido designamo-las de capabilities redistributivas - que seriam aquele conjunto de condições formais e materiais que tornariam os indivíduos capazes de viver uma vida concretamente digna, com direitos e deveres civis, condições materiais, de saúde, integridade física, etc. O segundo conjunto estaria vinculado às demandas de reconhecimento - que aqui chamamos de capabilities de reconhecimento - elas representam as condições sem as quais os indivíduos não podem adquirir uma autocompreensão positiva de si mesmos, por exemplo serem capazes de criar laços de amizade, de desenvolver suas emoções, de ter autorrespeito, etc. Por fim, propomos o grupo de capabilities atreladas à representação política - chamadas aqui de capabilities de representação política - que envolvem as condições de fundo necessárias para que haja a possibilidade efetiva de atuação dos indivíduos nos assuntos públicos, influenciando diretamente a formação da agenda política. Talvez esse novo modo de formular o limiar básico de capabilities (que se afaste da enumeração de itens específicos, em detrimento da discriminação de dimensões da justiça que deve abarcar) seja mais abrangente e propositadamente aberto - portanto, mais compatível com um modelo democrático - sem com isso perder de vista as filigranas das mais variadas dimensões que uma concepção de justiça requer para o tempo presente. Aqui, meramente, apresentamos as linhas gerais da discussão que pretendemos dar continuidade, com a sua devida profundida, em um outro momento.

\section{Considerações finais}

Neste artigo apresentamos a teoria parcial de justiça de Nussbaum, que é vinculada ao modelo das capabilities. Mostramos que seu projeto (como um todo) é mais amplo do que meramente a exposição de sua famosa lista. Para tanto, no primeiro momento do texto, defendemos que a abordagem de Nussbaum é de tipo top down, que propositadamente começa a partir de um nível mais abstrato de investigação e depois desce para assuntos mais concretos, como a implementação efetiva da teoria das capabilities - em oposição ao modelo bottom up como o de Sen que parte de questões concretas e depois sobe para aquelas mais abstratas. No 
segundo momento, adentramos propriamente na teoria parcial de justiça da autora, defendendo que ela pode ser desenvolvida em quatro estágios. O primeiro se refere à famosa elaboração da lista de capabilities. O segundo à justificação normativa da teoria. O terceiro a sua estabilidade. Por fim, o quarto à implementação da teoria. Seguindo as orientações da própria autora, defendemos que estudos seguintes que pretendem dar continuidade ao assunto cabem focar na relação entre democracia e a teoria das capabilities. Na atuação em conjunto das instituições domésticas, locais e globais que reside a possibilidade real da criação de um limiar básico das capabilities, que seja capaz de fornecer condições suficientes para uma vida digna. Sobre este ponto dedicamos a terceira seção, enfatizando o papel da estrutura política democrática e o conjunto de instituições que a abrange. Por fim, na quarta e última seção, argumentamos sobre as possíveis vantagens do modelo top down da autora, propondo o aprofundamento do limiar básico de capabilities de uma forma mais enxuta (mas não menos rica), compondo esse limiar por dimensões de redistribuição, de reconhecimento e de representação política. Dessa forma pretendemos oferecer, ao menos, o esboço de uma tentativa de reelaboração teórica da lista de capabilities da Nussbaum, que esteja mais diretamente conectada com uma estrutura política democrática. Nossa intuição de fundo é que um limiar básico de capabilities elaborado a partir dos três elementos fundamentais de justiça - detectadas por Fraser - seja, por um lado, capaz de defender Nussbaum das objeções de autoritarismo e perfeccionismo e, por outro, seja mais sensível a sua implementação de forma deliberativa e democrática. 


\title{
Notas
}

${ }^{1}$ Pós-doutorado - Bolsista FAPESP, Departamento de Ciência Política, na Universidade de São Paulo ( USP), São Paulo, S.P., Brasil. Este artigo é parte de um projeto que conta com o apoio de uma bolsa de Pós-Doutorado, processo no 2018/04606-4, Fundação de Amparo à Pesquisa do Estado de São Paulo (FAPESP). E-mail: nunzioali@gmail.com

2 Doutoranda do Programa de Pós-graduação em Filosofia da Universidade Federal de Santa Catarina (UFSC), Florianópolis, Santa Catarina, S. C., Brasil. O presente trabalho foi realizado com apoio da Coordenação de Aperfeiçoamento de Pessoal de Nível Superior - Brasil (CAPES) - Código de Financiamento 001. E-mail: dianapiroli@hotmail.com

\begin{abstract}
${ }^{3}$ Aqui, assim como Borges (2018) e Pinzani (2009), optamos por manter a terminologia em inglês capabilities e functionings, uma vez que acreditamos que a tradução - principalmente do primeiro termo para o português como "capacidades" - não condiz propriamente com a ideia total que subjaz o conceito. Capabilities, por exemplo, não se reduz meramente à ideia de capacidade. O termo capabilities é um termo original e cunhado especificamente para se referir aos conceitos dessa vertente teórica, portanto, é mais prudente continuar a se referir a ele no inglês. Quiçá, talvez possamos cogitar a possibilidade de uma possível inserção dos termos em português "capabilidades" e "funcionamentos" no jargão das teorias de justiça de nosso vernáculo, tal como propõe Borges (2018) e Pinzani (2009).
\end{abstract}

${ }^{4}$ Cita-se primeiramente as vantagens que distanciam a abordagem de Nussbaum da de Sen: (a) há um esforço em produzir argumentos normativos contra o relativismo cultural, (b) há uma fundamentação filosófica mais vigorosa com base em teorias precedentes, como a de Aristóteles e a de Rawls, (c) há uma lista de capabilities centrais que endossam um limiar básico de capabilities, (d) há uma especificação de três tipos de capabilities: básicas, internas e combinadas, (e) ela atua a nível doméstico, local e transnacional, (f) tem maior interlocução com o direito (law), ou melhor, sobre o papel do direito na teoria das capabilities, (g) articula sua teoria com as emoções e a imaginação política (NUSSBAUM, 2000, pp. 12-15).

${ }^{5}$ O destaque da expressão "limiar de capabilities" é proposital. Fazemos isto para destacar justamente a ênfase que a própria autora dá a esta concepção em seus últimos trabalhos, como em Fronteiras da Justiça (2013a) e Creating Capabilities (2011a). Trata-se, para ela, de argumentar que o papel da justiça e de suas instituições é justamente proteger e promover este limiar básico para a promoção suficiente de uma vida decente.

${ }^{6}$ Neste sentido a teoria parcial de justiça de Nussbaum pode ser classificada como uma abordagem "suficientarista", dado que ela argumenta que a distribuição de recursos deve ser suficiente para que todos os indivíduos que dela dependem alcancem certo limiar básico de recursos, que os permita viver de modo minimamente decente. Para outras abordagens suficientaristas $c f$. Crisp (2003), Frankfurt (2015). Uma observação crítica é formulada por Casal (2007).

${ }^{7}$ James Griffin em On Human rigths (2008) usa de modo similar a nomenclatura top down e bottom up, mas aplicada a concepção de direitos humanos, assim como Vittorio Bufacchi também o faz em Social Injustice (2012) para classificar dois modos distintos da construção de uma teoria da injustiça.

${ }^{8}$ Aqui não desenvolvemos as especificidades da ideia de justiça em Sen por conta de tempo e de espaço. $C f$. Sen (2009) e Robeyns $(2003,2005)$.

${ }^{9}$ Sobre as críticas à lista de capabilities de Nussbaum $c f$. Sen (2004), Robeyns (2003, 2005), Jaggar (2006).

${ }^{10}$ Uma comparação entre os trabalhos de Rawls e de Nussbaum pode ser encontrada em Romanelli (2012).

${ }^{11}$ Rawls (1999, pp. 347-348) distingue as teorias de bem em "fracas" (a thin theory of the good) e "abrangentes" (a full theory of the good). Uma concepção fraca se limita a endossar uma ideia parcial de bem, que seja meramente suficiente para definir os bens primários, isto é, o núcleo básico de elementos que fornecem as bases para desenvolver posteriormente uma concepção particular e abrangente de bem.

${ }^{12}$ Cf. Capítulo II de Creating Capabilities (2011a). 
${ }^{13}$ Nussbaum toma de empréstimo de Rawls (2001) a ideia de uma "utopia realista" ou de uma "utopia realizável" (realistic utopia). Com isso almeja indicar que sua concepção de justiça tem potenciais factíveis de realização inscritos na sua própria ideia.

14 Duas observações: (a) substituímos propositadamente a terminologia "capacidades" por "capibilities" da tradução de Fronteiras da Justiça (2013a) - sobre os motivos para isso conferir a primeira nota de rodapé deste artigo; (b) confrontamos a tradução e a formulação da lista com a mais recente publicação de Nussbaum (2019), onde ela mais uma vez elenca a lista de capabilities. Portanto, a lista aqui apresentada está atualizada.

15 O processo de validade normativa trabalhado por Nussbaum é similar ao de Rawls (1999), dado que até as terminologias utilizadas pela autora são tomadas de empréstimo dele, como no caso de "equilíbrio reflexivo", "liberalismo político" (NUSSBAUM, 2011a, 2013a).

${ }^{16}$ Sobre a exigência moral do universalismo na teoria de Nussbaum $c f$. Borges (2018).

${ }^{17}$ Nussbaum toma de Rawls (2001, p. 11) a distinção entre a aplicação da justiça à nível local, doméstico e global. Diz o autor: "Ao todo, temos três níveis de justiça, movendo-se por dentro e por fora: primeiro, a justiça local (cujos princípios são aplicáveis diretamente às instituições e associações); segundo, a justiça doméstica (cujos princípios são aplicáveis à estrutura básica da sociedade); e, finalmente, a justiça global (cujos princípios são aplicáveis ao direito internacional). A justiça como equidade começa com a justiça doméstica - a justiça da estrutura básica da sociedade. A partir disso, ela trabalha para fora em direção ao direito dos povos e internamente para a justiça local.” (RAWLS, 2001, p. 11).

${ }^{18}$ A concepção de "acordo transcultural" é principalmente recorrente nas obras Fronteiras da Justiça (2013a) $e$ Creating Capabilities (2011a). Para um aprofundamento desta ideia $c f$. Romanelli (2012).

19 A obra central de Nussbaum sobre emoções políticas é Political Emotions. Why Love matters for justice? (2013b), mas não podem ser negligenciadas as leituras The Monarchy of Fear (2018b) sobre o medo; Anger and Forgiveness: Resentment, Generosity, Justice (2018a), que lida com as emoções da raiva e da generosidade; Sem Fins Lucrativos: Por que a democracia precisa das humanidades (2015) que aborda a relação das emoções políticas com a educação; Hiding from Emotions: Disgust, Shame and the Law (2004) que analisa o nojo e a vergonha; Upheavals of Thought (2001) que contém a fundamentação da sua teoria cognitivista das emoções.

${ }^{20}$ Em Sem fins lucrativos: Por que a democracia precisa das humanidades (2015), por exemplo, pode-se encontrar uma proveitosa abordagem sobre o entrelaçamento entre emoções e política a partir das questões educacionais.

${ }^{21}$ Dez são os princípios normativos para a estruturação global das instituições, os quais aqui apresentamos sem aprofundá-los (NUSSBAUM, 2013a). O primeiro é o da sobredeterminação da reponsabilidade do Estado e dos seus indivíduos à nível doméstico sob o global. Em outras palavras, o princípio afirma ser responsabilidade primeira do estado (e da sua estrutura básica da sociedade) promover as condições institucionais necessárias para se atingir um limiar básico de capabilities. Dando sequência, o segundo princípio afirma que a soberania nacional do estado e de suas instituições devem ser respeitadas, evitando-se ao máximo tentativas de intervenção militar em prol de uma saída mais pacifista (próxima à persuasão e ao uso de fundos de apoio). Por sua vez, o terceiro princípio estabelece que, sob o ponto de vista da justiça global, se as nações mais prósperas possuem condições de auxiliar os mais pobres, então o devem fazer, pois elas também são responsáveis por mitigar a desigualdade global. Por exemplo, pode-se destinar certa parcela de seu produto interno bruto para as nações mais pobres. Quarto, as corporações multinacionais também são localmente responsáveis por promover o limiar básico das capabilities onde estão instaladas, dado que sob o ponto de vista econômico isso não somente gera futuros benefícios (como o fornecimento de uma mão de obra qualificada), como também sob o ponto de vista moral contribui para que os negócios sejam decentemente realizados, contribuindo com o meio ambiente e com a educação dos indivíduos, por exemplo. Quinto, as principais instituições da ordem econômica mundial devem ser equitativas (fair) com as nações pobres e em desenvolvimento. Sexto, deve-se encorajar uma esfera pública global descentralizada e, sobretudo, forte. Sétimo, a estrutura básica da sociedade, as instituições locais e as instituições globais devem focar nos problemas de desigualdade específicos de cada região. Oitavo, deve-se ter um cuidado especial com os doentes, os idosos, as crianças e os desfavorecidos. Nono, a família deve ser tratada como uma esfera privada, mas que também é regulamentada pela justiça. Neste sentido, rompe-se com a imagem da família como um núcleo da esfera privada intocável, a qual espontaneamente geraria as suas próprias regras de conduta. Décimo, todas as instituições (doméstica, local e global) têm a responsabilidade de promover a educação como forma de autonomia das pessoas desfavorecidas. Tomadas em conjunto, esses princípios formam o corpo normativo que orienta uma estruturação múltipla das instituições com vistas à promoção de um limiar básico das capabilities, orientando não somente o 
governo doméstico, o local, mas também o global. Certamente, pode-se questionar até que ponto esses princípios para a estruturação global das instituições não conflitam uns com outros. Por exemplo, o princípio da soberania dos Estados (I) e o princípio que determina o dever de atuação das nações mais ricas sobre os pobres (III). Não seria a sua relação problemática, dado que a "doação" pode atuar como chantagem e barganha política? Essa é uma provocação que aqui deixamos em aberto. Para um maior aprofundamento desses princípios $c f$. o capítulo cinco de Fronteiras da Justiça (2013a).

22 Algumas das críticas recebidas por Nussbaum podem ser encontradas em Sen (2004), Robeyns (2003, 2005), Crocker (2008), Claassen (2011) e Jaggar (2006).

${ }^{23}$ No quinto capítulo de Creating Capabilities (2011a) a autora dialoga sobre o futuro da teoria das capabilities, que na percepção dela estaria no desenvolvimento da: estrutura política democrática, questões climáticas, direitos dos animais, questões de gênero e como lidar com as carências e as vulnerabilidades.

${ }^{24}$ Cf. Sen (2004), Robeyns (2003, 2005), Crocker (2008), Claassen (2011) e Jaggar (2006).

${ }^{25}$ Aqui usamos como referência o trabalho de Romanelli (2012), na qual ela discute com profundida a ideia de um limiar básico de capabilities em Nussbaum.

${ }^{26}$ Nossa intenção não é a de promover uma aproximação profunda entre a teoria das capabilities de Nussbaum e a teoria crítica de Fraser. Nosso objetivo é menos pretencioso. Almejamos meramente pegar de empréstimo a defesa de Fraser sobre o carácter polissêmico da justiça, abrangendo três dimensões: redistribuição, reconhecimento e representação política.

\section{Referências}


BORGES, Maria de Lourdes. O feminismo universalista de Martha Nussbaum, ethic@ Florianópolis, Santa Catarina, Brasil, v. 17, n. 2, p. 205 - 216. Dez., 2018.

BUFACCHI, Vittorio. Social Injustice. Essays in Political Philosophy. UK: Palgrave Macmillan, 2012.

CASAL, Paula. Why sufficiency is not enough, Ethics, vol. 117, No. 2, pp. 296-326, 2007.

CLAASSEN, Rutger. Making capability lists: philosophy versus democracy. Political Studies, v. 59, p. 491-508, 2011.

CRISP, Roger. Equality Priority, and Compassion, Ethics, vol. 113, pp. 745-63, 2003.

CROCKER, David. Ethics of Global Development: Agency, Capability, and Deliberative Democracy. Maryland: Cambridge University, 2008.

FRANKFURT, Harry G. On Inequality. Princeton: Princeton University Press, 2015.

FRASER, Nancy. Scales of Justice. Reimagining Political Space in a Globalizing World. Columbia University Press, 2009.

- Social Justice in the Age of Identity Politics: Redistribution, Recognition, and Participation. IN: FRASER, Nancy; HONNETH, Axel. Redistribution or Recognition? A Political-Philosophical Exchange. Verso, London, 2003.

GRIFFIN, J. On Human Rights. Oxford: Oxford University Press, 2008.

JAGGAR, Alison M. Reasoning about well-being: Nussbaum's methods of justifying capabilities. The Journal of Political Philosophy, v. 14, n. 3, pp. 301-322, 2006.

NUSSBAUM, Martha. The Cosmopolitan Tradition. A Noble But Flawed Ideal. London: Belknap Press, 2019. . Anger and Forgiveness: Resentment, Generosity, Justice. USA: OUP, $2018 \mathrm{a}$.

. The Monarchy of Fear. A Philosopher Looks at our Political Crisis. New York: Simon \& Schuster, 2018 b.

; LEVMORE, Saul. Aging Thoughtfully. Conversations about Retirement, Romance, Wrinkles, and Regret. NY: Oxford Press, 2017. 
. Sem Fins Lucrativos: Por que a democracia precisa das humanidades. Tradução de Fernando Santos. SP: Martins Fontes, 2015.

. Fronteiras da justiça. Deficiência, Nacionalidade, Pertencimento à Espécie. Tradução de Susana de Castro. SP: WMF Martins Fontes, 2013a. $2013 b$.

Political Emotions: Why love matters for justice? Cambridge: Harvard University,

. Creating Capabilities: The Human Development Approach. Cambridge: Harvard University, 2011a. $\overline{3-45,2011 b .}$

. "Perfectionist Liberalism and Political Liberalism." Philosophy and Public Affairs 39:

. Capabilities, Entitlements, Rights. Supplementation and Critique. Journal of Human Development and Capabilities, Vol. 12, No. 1, February, p. 23-37, 2011c. 2004.

. Hiding from humanity: disgust, shame, and the law. US: Princeton University Press,

. 'Capabilities as fundamental entitlements', Feminist Economics, 9, pp. 33-59, 2003.

. Upheavals of Thought: The Intelligence of Emotions. US: Cambridge University Press, 2001.

. Women and Human Development: The Capabilities Approach. Cambridge: Cambridge University, 2000.

. 'Capabilities and human rights', Fordham Law Review, 66, pp. 273-300, 1997.

PINZANI, Alessandro. Reconhecimento e Solidariedade. Ethic@, Florianópolis v. 8, n. 3, pp. $101-113,2009$.

RAWLS, John. Justice as Fairness. A Restatement. Edited by Erin Kelly. Cambridge, MA: Harvard University Press, 2001.

. The Law of Peoples. Cambridge, MA: Harvard University Press, 2000.

. A Theory of Justice. Revised Edition. Cambridge: Harvard University, 1999. 
Political Liberalism. With a New Introduction and "The Reply to Habermas". New York: Columbia University, 1996.

ROBEYNS, Ingrid. Sen's capability approach and gender inequality: selecting relevant capabilities. Feminist Economics, v. 9, n. 2, p. 61-92, 2003.

Selecting capabilities for quality of life measurement. Social Indicators Research, v. 74, p. 191-215, 2005.

ROMANELLI, San Assumpção. Justiça e Gênero sob uma Perspectiva Cosmopolita. 2012. Tese (Doutorado em Ciência Política) - Departamento de Ciência Política, USP, São Paulo.

SANTOS, Tiago Mendonça dos. A Abordagem Das Capabilities de Sen E De Nussbaum: Um Estudo Comparativo. Revista de Teorias da Justiça, da Decisão e da Argumentação Jurídica,v. 4, n. 1, pp. $22-43,2018$.

SEN, Amartya. A ideia de justiça. Tradução de Denise Bottmann e Ricardo Doninelli Mendes. SP: Companhia das Letras, 2011.

Capabilities, lists, and public reason: continuing the conversation. Feminist Economics, v. 10 , n. 3 , p. $77-80,2004 a$. 